Original article

\title{
Invasive breast cancer over four decades reveals persisting poor metastatic outcomes in treatment resistant subgroup - the "ATRESS" phenomenon
}

\author{
Patriek Jurrius a, b, Thomas Green a, Hans Garmo a, Matthew Young a, \\ Massimiliano Cariati a, b, Cheryl Gillett a, Anca Mera ${ }^{a}$, Mark Harries ${ }^{\mathrm{a}, \mathrm{b}}$, \\ Anita Grigoriadis a, Sarah Pinder a, b, Lars Holmberg a,c, Arnie Purushotham ${ }^{\text {a, b, * }}$ \\ a School of Cancer \& Pharmaceutical Sciences, King's College London, Great Maze Pond, London, SE1 9RT, United Kingdom \\ ${ }^{\mathrm{b}}$ Guy's and St Thomas NHS Foundation Trust, Great Maze Pond, London, SE1 9RT, United Kingdom

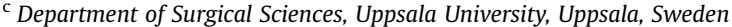

\section{A R T I C L E I N F O}

\section{Article history:}

Received 16 August 2019

Received in revised form 24 November 2019

Accepted 11 January 2020

Available online 14 January 2020

\section{Keywords:}

Breast cancer

Post-metastatic survival

ATRESS

Treatment resistance

Prognosis

\begin{abstract}
A B S T R A C T
Background: Major advances in breast cancer treatment have led to a reducuction in mortality. However, there are still women who are not cured. We hypothesize there is a sub-group of women with treatmentresistant cancers causing early death.

Methods: Between 1975 and 2006, 5392 women with invasive breast cancer underwent surgery at Guy's Hospital, London. Data on patient demographics, tumour characteristics, treatment regimens, local recurrence, secondary metastasis, and death were prospectively recorded. We considered four time periods (1975-1982, 1983-1990, 1991-1998, 1999-2006). Risks and time to event analysis were performed with Cox proportional hazards model and Kaplan-Meier estimation.

Results: Unadjusted hazard ratios for developing metastasis and overall mortality relative to the 1975 -1982 cohort decreased steadily to 0.23 and 0.63 , respectively in 1999-2006. However, metastasis-free interval shortened, with the proportion of women developing metastasis $\leq 5$ years increasing from $73.9 \%$ to $83.0 \%$. Furthermore, median post-metastatic survival decreased from 1.49 years to 0.94 years. Applying our risk criteria identified the presence of \pm 200 patients in each cohort who developed metastasis early and died within a much shorter time frame.

Conclusions: Advances in treatment have decreased the risk of metastasis and improved survival in women with invasive breast cancer over the last 40 years. Despite this, a subpopulation with shorter metastasis-free and post-metastatic survival who are unresponsive to available treatment remains. This may be due to the ATRESS phenomenon (adjuvant therapy-related shortening of survival) secondary to preselection inherent in adjuvant therapy, successful treatment of less malignant tumour cells and treatment-induced resistance in the remaining tumour clones.
\end{abstract}

๑ 2020 The Authors. Published by Elsevier Ltd. This is an open access article under the CC BY-NC-ND license (http://creativecommons.org/licenses/by-nc-nd/4.0/).

\section{Introduction}

Breast cancer has been at the forefront of cancer research over the last 40 years. This has led to a $32 \%$ reduction of breast cancer mortality in the United Kingdom (UK) since the early 1970s [1]. However, despite earlier detection and improvements in treatment,

\footnotetext{
* Corresponding author. Research Oncology, 3rd floor, Bermondsey Wing, Guy's Hospital, Great Maze Pond, London, SE1 9RT, United Kingdom.

E-mail address: arnie.purushotham@kcl.ac.uk (A. Purushotham).
}

some women do not respond thereby resulting in metastatic disease and death. We hypothesized that there is a sub-group of women consistently present over the last several decades who have cancers that are inherently resistant to therapy. To test this hypothesis, the changes in outcomes and patterns of response to treatment in breast cancer patients treated over 40 years were assessed.

\section{Material and methods}

Between January 1975 and December 2006, a total of 6361 
women were diagnosed with invasive breast cancer at Guy's Hospital in London. Data, including patient demographics, tumour characteristics, treatment modality, and follow-up data on local recurrence, pattern of metastasis and death, were prospectively recorded. Patients were excluded from analysis if their initial surgery took place more than six months after initial diagnosis, based on the assumption that a delayed surgery of more than six months would not have corresponded to routine treatment standards and was most likely for reasons outside normal clinical care. Women receiving neo-adjuvant chemotherapy were included in this study.

\subsection{Time period cohorts}

Women were divided into four different time periods based on year of surgery: 1975-1982, 1983-1990, 1991-1998, 1999-2006, denoted P1, P2, P3, and P4. The time periods were selected to divide the study subjects into four similarly sized cohorts. They also coincided with periods of change in breast cancer care in the UK, such as the introduction of tamoxifen (1972), 5-fluorouracil chemotherapy (1976), anthracyclines (1980s), taxanes (1990s) and trastuzumab (Herceptin $\left.{ }^{\circledR}\right)(2001)$ and the introduction of the National Health Service Breast Screening Programme (NHSBSP) (1988) [2-6].

\subsection{Statistical analyses}

The four periods were compared based on patient outcome with regard to time to distant metastases, time from metastases to death, and overall survival, by means of Cox proportional hazards model summarised by hazard ratios (HR) and 95\%-confidence intervals (95\%-CI). Kaplan-Meier estimation was used to graphically illustrate time to event analysis.

\subsection{Follow-up}

To ensure follow-up times in the different surgery year groups were comparable, the following dates for end of follow-up were applied: for P1 June 1991; for P2 June 1999; for P3 June 2007; and for P4 June 2015 making all analyses limited to a maximum followup of approximately 16 years.

\subsection{Overall survival from primary disease}

In a first analysis, the overall survival from date of surgery to date of death or end of follow-up, whichever came first, was compared. The model was adjusted for an increasing set of predetermined potentially confounding factors, including biological characteristics of the carcinoma (invasive tumour size, nodal status, histological grade, oestrogen receptor (ER), progesterone receptor (PgR) and human epidermal growth factor receptor 2 (HER2)), and adjuvant/neoadjuvant treatments (chemotherapy, radiotherapy and endocrine treatment) in combination with surgery.

Methods of determining ER and PgR status varied over the study period. When enzyme immunoassay (EIA) was used, a positive result cut-off was defined as $>15 \mathrm{fmol} / \mathrm{mg}$ protein, for the dextrancoated charcoal (DCC) ligand binding assay the cut-off was $>20 \mathrm{fmol} / \mathrm{mg}$ and for immunochemistry (IHC) either a Quick score divided as $0-3$ versus $4-7$ or subsequently the Allred score $0-2$ versus $3-8$ were applied [7-10]. For HER2 status, IHC was used as the first line test, according to UK HER2 testing guidelines, with scores of $0-1$ (negative) versus score 3 (positive) [10-12]. Equivocal results (score $2+$ ) were further assessed using fluorescence in situ hybridisation (FISH) and a ratio of $>2.00$ of HER2 gene to chromosome 17 centromeric probe was defined as HER2 amplified for this series [10-12].

\subsection{Overall survival from onset of metastasis}

The proportion of women developing secondary distant metastases $\leq 8$ years from surgery was examined. De novo metastatic disease has not been included. The women with distant metastases were further subdivided into four categories, determined by the proportions of deaths occurring $\leq 1$ year, from 1 to $2,2-4$, and $4+$ years from the date of diagnosis of distant metastases.

\subsection{Onset of metastasis}

In a further analysis, the four time periods were compared regarding time from surgery to time to development of secondary distant metastases; this was defined as the date of clinical diagnosis of metastasis or date of death in case of post-mortem metastatic disease diagnosis (P1: $\mathrm{n}=37, \mathrm{P} 2: \mathrm{n}=34, \mathrm{P} 3: \mathrm{n}=40, \mathrm{P} 4: \mathrm{n}=24)$, the date of breast cancer-related death or last follow-up, whichever came first. The same set of models adjusting for potential confounders as above was used. Finally, a comparison was made between the four time periods for variation in time from diagnosis of distant metastases to death or end of follow-up, whichever came first. In addition to the potential confounders presented above, all treatments administered during the whole period, from first diagnosis to those treatments prescribed for metastatic disease, were included in this analysis.

\subsection{Risk groups}

To identify various risk groups in each time period, women were categorized based on the St. Gallen breast cancer risk criteria and the histological grade of the primary tumour, both independent of each other important verified prognostic features [13]. The three resulting groups were defined as follows: low risk = St. Gallen low and intermediate risk categories; intermediate risk $=$ St. Gallen high risk category (i.e. node positive (1-3 nodes) AND ER \& PgR negative OR HER2 overexpressed/amplified OR just $\geq 4$ lymph nodes involved) with grade 1 or 2 invasive breast cancer; high risk $=$ St. Gallen high risk category, with grade 3 invasive breast cancer (detailed definition in Table 1).

\subsection{Missing data}

For missing data, multiple imputations by chained equations (MICE) were performed to complete the dataset. All statistical analyses were performed using the statistical program package $\mathrm{R}$ (http://www.R-project.org).

\section{Results}

\subsection{Surgery}

Of the total 6361 women diagnosed with invasive breast cancer, $5392(84.8 \%)$ underwent surgery within 6 months of first diagnosis. For the 4 time periods the percentage receiving surgery within 6 months after diagnosis was $83.7 \%, 83.1 \%, 87.6 \%$, and $84.8 \%$ respectively. The basic patient demographics, tumour characteristics, and treatment modalities for those women who underwent surgery can be seen in Table 2 .

\subsection{Overall survival from diagnosis}

The risk of dying from breast cancer progressively decreased for each consecutive time period; the unadjusted data showed a decrease in risk of dying of on average $37 \%$ over the four decades. HRs relative to those women in the earliest time period 
Table 1

Definitions of risk categories as per St Gallen 2007 and as devised in this research for patients with operable breast cancer.

\begin{tabular}{|c|c|c|}
\hline Risk category & St Gallen criteria & Our risk criteria \\
\hline Low risk & $\begin{array}{l}\text { Node negative AND Grade } \mathbf{1}^{\mathrm{a}} \text { AND } \\
\mathrm{pT}^{\mathrm{b}} \leq 2 \mathrm{~cm} \text {, AND } \\
\text { Absence of extensive peritumoral vascular invasion, AND } \\
\text { ER and/or PgR }{ }^{\mathrm{c}} \text { expressed, AND } \\
\text { HER2/neu gene neither overexpressed nor amplified, AND } \\
\text { Age } \geq 35 \text { years }\end{array}$ & $\begin{array}{l}\text { Node negative AND Grade } \mathbf{1}^{\mathrm{a}} \text { AND } \\
\mathrm{pT}^{\mathrm{b}} \leq 2 \mathrm{~cm}, \text { AND } \\
\text { With or without extensive peritumoral vascular invasion, AND } \\
\text { ER and/or PgR expressed, AND } \\
\text { HER2/neu gene neither overexpressed nor amplified, AND } \\
\text { Age } \geq 35 \text { years } \\
\text { OR } \\
\text { Node negative AND } \\
\mathrm{Grade}^{\mathrm{C}} 23^{\mathrm{a}} \text {, OR } \\
\mathrm{pT}^{\mathrm{b}}>2 \mathrm{~cm} \text {, OR } \\
\text { Presence of extensive peritumoral vascular invasion, OR } \\
\text { ER and PgR absent, OR } \\
\text { HER2/neu gene overexpressed or amplified, OR } \\
\text { Age }<35 \text { years } \\
\text { OR } \\
\text { Node positive (1-3 involved nodes) AND } \\
\text { ER and/or PgR expressed, AND } \\
\text { HER2/neu gene neither overexpressed nor amplified }\end{array}$ \\
\hline Intermediate risk & $\begin{array}{l}\text { Node negative AND } \\
\text { Grade } 2-3^{\mathrm{a}} \text {, OR } \\
\mathrm{pT}^{\mathrm{b}}>2 \mathrm{~cm} \text {, OR } \\
\text { Presence of extensive peritumoral vascular invasion, OR } \\
\text { ER and PgR absent, OR } \\
\text { HER2/neu gene overexpressed or amplified, OR } \\
\text { Age }<35 \text { years } \\
\text { OR } \\
\text { Node positive (1-3 involved nodes) AND } \\
\text { ER and/or PgR expressed, AND } \\
\text { HER2/neu gene neither overexpressed nor amplified }\end{array}$ & $\begin{array}{l}\text { Node positive (1-3 involved nodes) AND } \underline{\text { Grade } 1-2^{\text {a }}} \text { AND } \\
\text { ER and PgR absent, OR } \\
\text { HER2/neu gene overexpressed or amplified } \\
\text { OR } \\
\text { Node positive (4 or more involved nodes) AND } \underline{\text { Grade } \mathbf{1 - 2}^{\text {a }}}\end{array}$ \\
\hline High risk & $\begin{array}{l}\text { Node positive (1-3 involved nodes) AND } \\
\text { ER and PgR absent, OR } \\
\text { HER2/neu gene overexpressed or amplified } \\
\text { OR } \\
\text { Node positive ( } 4 \text { or more involved nodes) }\end{array}$ & $\begin{array}{l}\text { Node positive (1-3 involved nodes) AND Grade } 3^{\text {a }} \text { AND } \\
\text { ER and PgR absent, OR } \\
\text { HER2/neu gene overexpressed or amplified } \\
\text { OR } \\
\text { Node positive ( } 4 \text { or more involved nodes) AND Grade } 3^{\text {a }}\end{array}$ \\
\hline
\end{tabular}

(1975-1982) diminished over time. Overall survival was positively associated with receiving (neo)adjuvant radio-, (neo)adjuvant chemo- and adjuvant endocrine therapy, with changes in HR from 0.72 in P3 and 0.64 in P4 to 0.77 and 0.69 respectively when adjusted for these treatment modalities (Table 3 ).

\subsection{Risk of metastasis}

Using the Kaplan-Meier estimator, the probability of developing metastasis at 8 years after diagnosis successively diminished over each time period from $42 \%$ in P1, to $35 \%$ in $\mathrm{P} 2,22 \%$ in $\mathrm{P} 3$, and $9 \%$ in P4. This constitutes a HR of 0.23 (95\%-CI 0.19-0.27) for development of metastasis for P4 compared to P1 (Table 4). The percentage of tumours $<2 \mathrm{~cm}$ increased from $29.1 \%$ to $47.4 \%$, with the percentage of women receiving (neo)adjuvant radio-, (neo)adjuvant chemo- and adjuvant endocrine therapy equally increasing (Table 2). Yet, the covariates of tumour size, nodal status, histological grade, histological type, ER-status, PgR-status, (neo)adjuvant chemo-, (neo)adjuvant radio-, and adjuvant endocrine therapy did not individually substantially influence the HR for developing distant metastases (Table 4). The proportion of women with a local recurrence who subsequently developed metastasis decreased from $53.1 \%$ in P1 through to $25.4 \%$ in P4 (Table 5).

\subsection{Onset of metastasis}

Table 5 shows patient demographics, histopathological characteristics, and treatment modalities for those women who developed secondary metastasis. The proportion of women developing metastasis $\leq 5$ years after primary surgery decreased slightly from P1 to P3 (73.9\%, 72.0\%, and 70.7\% respectively), but increased again to $83.0 \%$ in P4. The most marked difference was for the group of women developing metastasis $\leq 1$ year; this proportion of women initially decreased from $18.6 \%$ to $16.5 \%$ and $11.2 \%$ for P1 to P3 respectively, but then nearly doubled to $21.2 \%$ in $\mathrm{P} 4$.

\subsection{Overall survival from onset of metastasis}

In women who developed metastasis, the median survival after diagnosis of metastasis decreased from 1.49 years (95\%-CI $1.32-1.69)$ in $\mathrm{P} 1$ to 1.25 years $(95 \%-\mathrm{CI} 1.06-1.47), 0.85$ years $(95 \%-\mathrm{CI}$ $0.65-1.01)$ and 0.94 years $(95 \%-\mathrm{CI} 0.61-1.32)$ in P2, P3, and P4 respectively - a decrease of 6.6 months in survival from onset of metastasis over the 40-year period (Fig. 1A).

In unadjusted analysis, women in P4 had a $43 \%$ higher chance of dying from metastasis compared to P1, during a median follow-up of 1.2 years (Table 6). From adjusted model 5 (see Table 6 ) onwards, where the HRs were adjusted for (neo)adjuvant radio-, (neo)adjuvant chemo-, and adjuvant endocrine therapy rather than only histopathological features, the HR in P4 versus P1 diminished from 1.28 to 1.02. Additional adjustments for the treatment of local recurrence and distant metastases, resulted in a consistent HR for P4 versus P1.

\subsection{High risk subpopulation}

Applying selection criteria based on the St. Gallen criteria and the grade of the primary tumour, subsets of women with similar 
Table 2

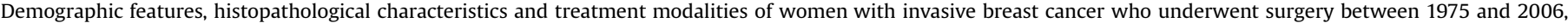
divided into four time periods.ER = oestrogen receptor, PgR = progesterone receptor, HER2 = human epithelial growth factor receptor 2 .

\begin{tabular}{|c|c|c|c|c|c|c|c|c|}
\hline \multirow{2}{*}{ Age at diagnosis, n (\%) } & \multicolumn{2}{|c|}{$\begin{array}{l}1975-1982 \\
(\mathrm{n}=1381)\end{array}$} & \multicolumn{2}{|c|}{$\begin{array}{l}1983-1990 \\
(n=1333)\end{array}$} & \multicolumn{2}{|c|}{$\begin{array}{l}1990-1998 \\
(n=1382)\end{array}$} & \multicolumn{2}{|c|}{$\begin{array}{l}1999-2006 \\
(n=1296)\end{array}$} \\
\hline & & & & & & & & \\
\hline$<40$ & 105 & $(7.6)$ & 124 & $(9.3)$ & 112 & $(8.1)$ & 130 & $(10.0)$ \\
\hline $40-49$ & 362 & $(26.2)$ & 254 & $(19.1)$ & 296 & $(21.4)$ & 242 & (18.7) \\
\hline $50-59$ & 406 & $(29.4)$ & 371 & $(27.8)$ & 393 & $(28.4)$ & 354 & $(27.3)$ \\
\hline $60-69$ & 305 & $(22.1)$ & 350 & (26.3) & 309 & $(22.4)$ & 294 & (22.7) \\
\hline $70+$ & 203 & $(14.7)$ & 234 & $(17.6)$ & 272 & $(19.7)$ & 276 & $(21.3)$ \\
\hline \multicolumn{9}{|l|}{ Nodal status, n (\%) } \\
\hline Negative & 621 & $(45.0)$ & 576 & $(43.2)$ & 603 & $(43.6)$ & 549 & $(42.4)$ \\
\hline Positive & 601 & $(43.5)$ & 580 & $(43.5)$ & 632 & $(45.7)$ & 500 & $(38.6)$ \\
\hline Missing & 159 & $(11.5)$ & 177 & (13.3) & 147 & $(10.6)$ & 247 & (19.1) \\
\hline \multicolumn{9}{|l|}{ Nodal number, n (\%) } \\
\hline 0 & 621 & $(45.0)$ & 576 & $(43.2)$ & 603 & $(43.6)$ & 549 & $(42.4)$ \\
\hline $1-3$ & 352 & $(25.5)$ & 354 & $(26.6)$ & 403 & $(29.2)$ & 335 & $(25.8)$ \\
\hline $4+$ & 249 & $(18.0)$ & 226 & $(17.0)$ & 229 & $(16.6)$ & 165 & (12.7) \\
\hline Missing & 159 & $(11.5)$ & 177 & $(13.3)$ & 147 & $(10.6)$ & 247 & (19.1) \\
\hline \multicolumn{9}{|l|}{ Tumour size, n (\%) } \\
\hline$<2 \mathrm{~cm}$ & 402 & $(29.1)$ & 479 & $(35.9)$ & 757 & $(54.8)$ & 614 & $(47.4)$ \\
\hline $2-5 \mathrm{~cm}$ & 892 & $(64.6)$ & 780 & $(58.5)$ & 556 & $(40.2)$ & 580 & $(44.8)$ \\
\hline $5+\mathrm{cm}$ & 56 & $(4.1)$ & 52 & $(3.9)$ & 53 & $(3.8)$ & 68 & $(5.2)$ \\
\hline Missing & 31 & $(2.2)$ & 22 & $(1.7)$ & 16 & $(1.2)$ & 34 & $(2.6)$ \\
\hline \multicolumn{9}{|l|}{ Histological type, n (\%) } \\
\hline Ductal & 1113 & $(80.6)$ & 1088 & $(81.6)$ & 1115 & $(80.7)$ & 964 & $(74.4)$ \\
\hline Lobular & 122 & $(8.8)$ & 154 & (11.6) & 166 & $(12.0)$ & 105 & $(8.1)$ \\
\hline Other/missing & 146 & $(10.6)$ & 91 & $(6.8)$ & 101 & $(7.3)$ & 227 & $(17.5)$ \\
\hline Grade, n (\%) & & & & & & & & \\
\hline Grade 1 & 131 & $(9.5)$ & 141 & $(10.6)$ & 233 & $(16.9)$ & 178 & (13.7) \\
\hline Grade 2 & 620 & (44.9) & 543 & $(40.7)$ & 400 & $(28.9)$ & 456 & (35.2) \\
\hline Grade 3 & 371 & $(26.9)$ & 418 & $(31.4)$ & 520 & $(37.6)$ & 434 & $(33.5)$ \\
\hline Unknown/missing & 259 & $(18.8)$ & 231 & $(17.3)$ & 229 & $(16.6)$ & 228 & (17.6) \\
\hline ER-status, n (\%) & & & & & & & & \\
\hline Negative & 437 & $(31.6)$ & 346 & $(26.0)$ & 298 & $(21.6)$ & 231 & $(17.8)$ \\
\hline Positive & 786 & (56.9) & 899 & $(67.4)$ & 978 & $(70.8)$ & 904 & (69.8) \\
\hline Missing & 158 & $(11.4)$ & 88 & $(6.6)$ & 106 & $(7.7)$ & 161 & $(12.4)$ \\
\hline PgR-status, n (\%) & & & & & & & & \\
\hline Negative & 627 & $(45.4)$ & 600 & $(45.0)$ & 500 & $(36.2)$ & 384 & $(29.6)$ \\
\hline Positive & 534 & $(38.7)$ & 638 & $(47.9)$ & 776 & $(56.2)$ & 752 & $(58.0)$ \\
\hline Missing & 220 & $(15.9)$ & 95 & $(7.1)$ & 106 & $(7.7)$ & 160 & $(12.3)$ \\
\hline HER2-status, n (\%) & & & & & & & & \\
\hline Negative & 404 & $(29.3)$ & 573 & $(43.0)$ & 660 & $(47.8)$ & 689 & $(53.2)$ \\
\hline Positive & 110 & $(8.0)$ & 157 & $(11.8)$ & 177 & $(12.8)$ & 197 & $(15.2)$ \\
\hline Missing & 867 & $(62.8)$ & 603 & $(45.2)$ & 544 & $(39.4)$ & 410 & (31.6) \\
\hline High risk subpopulation $^{\mathrm{a}}$ & & & & & & & & \\
\hline St Gallen 'High Risk' + Grade 3 & 177 & $(12.8)$ & 183 & $(13.7)$ & 222 & $(16.1)$ & 196 & $(15.1)$ \\
\hline Other/missing & 1204 & $(87.2)$ & 1150 & $(86.3)$ & 1160 & $(83.9)$ & 1100 & $(84.9)$ \\
\hline Surgery, n (\%) & & & & & & & & \\
\hline Mastectomy & 1177 & $(85.2)$ & 671 & $(50.3)$ & 546 & $(39.5)$ & 513 & $(39.6)$ \\
\hline Breast conservation & 204 & $(14.8)$ & 662 & $(49.7)$ & 836 & $(60.5)$ & 783 & $(60.4)$ \\
\hline (Neo)adjuvant Radiation therapy, n (\%) & & & & & & & & \\
\hline Yes & 250 & $(18.1)$ & 550 & $(41.3)$ & 817 & $(59.1)$ & 877 & $(67.7)$ \\
\hline No & 1131 & $(81.9)$ & 783 & $(58.7)$ & 565 & $(40.9)$ & 419 & $(32.3)$ \\
\hline Adjuvant endocrine therapy, n (\%) & & & & & & & & \\
\hline No endocrine therapy & 1333 & $(96.5)$ & 891 & $(66.8)$ & 336 & $(24.3)$ & 591 & $(45.6)$ \\
\hline Adjuvant endocrine therapy & 47 & $(3.4)$ & 441 & $(33.1)$ & 1036 & $(75.0)$ & 679 & $(52.4)$ \\
\hline Neoadjuvant endocrine therapy & 1 & $(0.1)$ & 1 & $(0.1)$ & 9 & $(0.7)$ & 24 & $(1.9)$ \\
\hline Neoadjuvant + adjuvant endocrine therapy & 0 & $(0.0)$ & 0 & $(0.0)$ & 1 & $(0.1)$ & 2 & $(0.2)$ \\
\hline Type of endocrine therapy, $n$ (\%) & & & & & & & & \\
\hline Aromatase Inhibitor \pm tamoxifen & 0 & $(0.0)$ & 0 & $(0.0)$ & 5 & $(0.4)$ & 76 & $(5.9)$ \\
\hline Tamoxifen & 44 & $(3.2)$ & 397 & $(29.8)$ & 1032 & $(74.7)$ & 629 & $(48.5)$ \\
\hline Ovarian ablation & 3 & $(0.2)$ & 42 & $(3.2)$ & 5 & $(0.4)$ & 0 & $(0.0)$ \\
\hline Other endocrine therapy & 1 & $(0.1)$ & 3 & $(0.2)$ & 4 & $(0.3)$ & 0 & $(0.0)$ \\
\hline No endocrine therapy & 1333 & $(96.5)$ & 891 & $(66.8)$ & 336 & $(24.3)$ & 591 & $(45.6)$ \\
\hline (Neo)adjuvant chemotherapy, n (\%) & & & & & & & & \\
\hline No chemotherapy & 1182 & $(85.6)$ & 1180 & $(88.5)$ & 967 & $(70.0)$ & 794 & $(61.3)$ \\
\hline Adjuvant chemotherapy & 199 & $(14.4)$ & 148 & $(11.1)$ & 358 & $(25.9)$ & 449 & $(34.6)$ \\
\hline Neoadjuvant chemotherapy & 0 & $(0.0)$ & 5 & $(0.4)$ & 47 & $(3.4)$ & 43 & $(3.3)$ \\
\hline Neoadjuvant + adjuvant chemotherapy & 0 & $(0.0)$ & 0 & $(0.0)$ & 10 & $(0.7)$ & 10 & $(0.8)$ \\
\hline Type of chemotherapy, n (\%) & & & & & & & & \\
\hline Taxanes \pm Anthracyclines & 0 & $(0.0)$ & 0 & $(0.0)$ & $4^{\mathrm{b}}$ & $(0.3)$ & 33 & $(2.5)$ \\
\hline Anthracyclines & 72 & $(5.2)$ & 153 & $(11.5)$ & 399 & $(28.9)$ & 468 & $(36.1)$ \\
\hline Other chemotherapy & 127 & $(9.2)$ & 0 & $(0.0)$ & 12 & $(0.9)$ & 1 & $(0.1)$ \\
\hline No chemotherapy & 1182 & $(85.6)$ & 1180 & $(88.5)$ & 967 & $(70.0)$ & 794 & (61.3) \\
\hline
\end{tabular}

a Based on the mean of 5 imputation datasets.

b 1 Woman received taxanes alone. 
Table 3

Risk of mortality from date of surgery for each cohort and adjusted for various potential covariates.

\begin{tabular}{llllllllll}
\hline Model & 1975 \\
& -1982 & & $1983-1990$ & $1991-1998$ & \multicolumn{1}{l}{$1999-2006$} \\
\hline 1 & 1.00 & Ref. & 0.89 & $(0.80-0.99)$ & 0.69 & $(0.62-0.78)$ & 0.63 & $(0.56-0.71)$ \\
2 & 1.00 & Ref. & 0.88 & $(0.79-0.98)$ & 0.72 & $(0.64-0.80)$ & 0.63 & $(0.56-0.70)$ \\
3 & 1.00 & Ref. & 0.89 & $(0.80-1.00)$ & 0.72 & $(0.65-0.81)$ & 0.64 & $(0.57-0.72)$ \\
4 & 1.00 & Ref. & 0.93 & $(0.83-1.04)$ & 0.77 & $(0.67-0.90)$ & 0.69 & $(0.60-0.81)$ \\
\hline
\end{tabular}

Model 1: Crude analysis.

Model 2: Adjusted Tumour size $(<2 \mathrm{~cm} / 2-5 \mathrm{~cm} / 5+\mathrm{cm})$, Nodal status (Negative/ Positive), and age.

Model 3: As Model 2 with further adjustment for Tumour grade (Grade 1/Grade 2/ Grade 3), Histological type (Ductal/Lobular/Tubular/Other), ER-status (Negative/ Positive), and PgR-status (Negative/Positive), and Her2-status (Negative/Positive).

Model 4: As Model 3 with further adjustment for (neo)adjuvant Chemotherapy (Yes/No), (neo)adjuvant Radiotherapy (Yes/No), and adjuvant Endocrine treatment (Yes/No) regarding primary tumour.

Table 4

Risk of distant metastases from year of surgery for each cohort and adjusted for various potential covariates.

\begin{tabular}{|c|c|c|c|c|}
\hline Model & $\begin{array}{l}1975 \\
-1982 \\
\text { (number } \\
\text { of events: } \\
612 \text { ) }\end{array}$ & $\begin{array}{l}\text { 1983-1990 } \\
\text { (number of } \\
\text { events: } 504 \text { ) }\end{array}$ & $\begin{array}{l}\text { 1991-1998 } \\
\text { (number of } \\
\text { events: } 348 \text { ) }\end{array}$ & $\begin{array}{l}\text { 1999-2006 } \\
\text { (number of } \\
\text { events: } 158 \text { ) }\end{array}$ \\
\hline 1 & 1.00 Ref. & $0.79 \quad(0.70-0.89)$ & $0.48 \quad(0.42-0.55)$ & $0.23(0.19-0.27)$ \\
\hline 2 & 1.00 Ref. & $0.81 \quad(0.72-0.91)$ & $0.51 \quad(0.45-0.59)$ & $0.24 \quad(0.20-0.28)$ \\
\hline 3 & 1.00 Ref. & $0.82(0.72-0.92)$ & $0.52 \quad(0.45-0.59)$ & $0.24 \quad(0.20-0.29)$ \\
\hline 4 & 1.00 Ref. & $0.81 \quad(0.71-0.93)$ & $0.53 \quad(0.44-0.63)$ & $0.23 \quad(0.19-0.29)$ \\
\hline
\end{tabular}

Model 1: Crude analysis.

Model 2: Adjusted Tumour size $(<2 \mathrm{~cm} / 2-5 \mathrm{~cm} / 5+\mathrm{cm}$ ), Tumour grade (Grade 1/ Grade $2 /$ Grade 3 ), and age.

Model 3: As Model 2 with further adjustment for Nodal status (Negative/Positive), Histological type (Ductal/Lobular/Tubular/Other), ER-status (Negative/Positive), and PgR-status (Negative/Positive), and Her2-status (Negative/Positive).

Model 4: As Model 3 with further adjustment for (neo)adjuvant Chemotherapy (Yes/No), neo(adjuvant) Radiotherapy (Yes/No), and adjuvant Endocrine treatment (Yes/No) regarding primary tumour.

prognostic features were extracted from the cohort. ${ }^{15}$ Within all four time periods a subset of a similar number of women - P1: 177, P2: 183, P3: 222 and P4: 196 - with the high-risk St. Gallen Criteria and tumour grade 3 was identified (Fig. 2). From this high-risk subset, the overall survival of those women developing metastasis was plotted (Fig. 1B), showing that the mortality probability was similar for these women across the four time periods.

\section{Discussion}

As previously described $[1,14,15]$ the overall survival from breast cancer improved over four decades by approximately $40 \%$ and the risk of developing metastasis decreased by $80 \%$. The decrease of HR for overall mortality between 1983-1990 and 1991-1998 in this study is likely to be due to a combination of the introduction of the NHSBSP in 1988 and better treatment modalities [5,16]. However, when adjusting for tumour size and nodal status, i.e. surrogate markers of earlier detection, only a negligible change in the HRs was seen in P3 and P4 compared with P1 suggesting that lead-time bias is not a significant factor in the increased survival noted. Conversely, the increase in mortality HR from 0.63 (crude analysis) to the adjusted HR of 0.69 in the last time period (P4) suggests that (neo)adjuvant radiotherapy, (neo)adjuvant chemotherapy and adjuvant endocrine therapy are more important contributors to the improvement in overall survival (Table 3 ).

The number of women with primary operable breast cancer who subsequently developed metastasis decreased during each time period analysed. This could also have been anticipated with advances in screening and treatment [17-20]. However, these data show that none of the tumour characteristics, (neo) adjuvant radiotherapy, (neo)adjuvant chemotherapy or adjuvant endocrine therapy fully account for this decreasing risk of metastasis over the studied time period. Within each time group, when compared to the first cohort, the HRs are consistent over all of the adjustment models, for example, approximately $78 \%$ reduction in risk for all adjustment models in P4 compared to P1. To understand this pattern, individual data on screening exposure and correction for lead-time would be necessary. There is a theoretical possibility that treatment interacts with early, pre-symptomatic detection to make the treatment more effective, which partly would explain the findings. Furthermore, to tease out the problem, individual data on detection mode of distant metastases would be needed; improved diagnostics and changed criteria over time means that both women with and without metastases in the four cohorts differ. However, concerning the latter, it is probable that our estimates of a drift towards shorter survival after distant metastases are conservative. Local recurrence, following breast-conserving surgery and postoperative radiotherapy, is a well-recognised independent risk factor for distant metastasis [21]. The reduction in local recurrence observed over the time period is also likely to have contributed to the decrease in metastasis [22].

Despite the overall decline in the risk of development of secondary metastasis over the time periods, in those women who developed metastasis, the proportion who did so within 1 year of diagnosis was highest in the most recent time period (22.1\%). The median survival from the time of diagnosis of metastatic disease also diminished from 1.49 years to 0.94 years over the 4 decades, with an increase in mortality risk of $40 \%$.

It is recognised that women with a shorter distant metastasis free interval (DMFI) have a shorter survival time following development of the metastasis [23,24] and that receptor status, e.g. HER2 positive and triple negative disease, correlates with a higher risk of (early) metastatic disease [25,26]. In this series, tumours in women who subsequently developed metastatic disease showed consistent ER- and PgR-expression over the four time periods, whereas the proportion of HER2 positive disease increased over the years. Assessment of HER2 expression was standard from halfway through P2 onwards, thereby explaining the apparent increase in HER2 positive cases in later cohorts [12].

The mean survival time following diagnosis with metastasis decreased from 17.9 months in the first time period, to 15 months, 10.2 months and 11.3 months in P2, P3, and P4, respectively. This is in contrast to several other studies where an increase in survival over time after diagnosis of distant disease has been reported [27-30]. Of these studies Andre et al. report on synchronous metastases [27] and Ernst et al. primary metastatic breast cancer [29] rather than secondary metastatic disease. The women in these studies will therefore not have received adjuvant chemotherapy prior to their metastatic treatment. Giordano et al. combined local relapse and distant metastases in their evaluation, impeding interpretation in the context of this study [28]. Lastly, Chia et al. describe a decreased post-metastatic use of anthracyclines and an increase of taxanes with an improved survival from metastatic breast cancer between 1991 and 2001 [30]. Other studies, however, have described similar findings to those reported here with shorter overall survival from metastatic breast cancer [31-38]. A large German multi-centre study evaluating 60,227 breast cancer patients found an increasing cure rate as a result of improved systemic treatment and a similar reduction in post-metastatic survival over a comparable time period (1978-2013) [34]. Recently, a comprehensive overview of post-metastatic shortening of survival and the 
Table 5

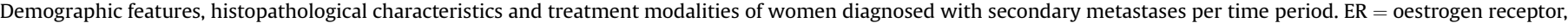
$\operatorname{PgR}=$ progesterone receptor, HER2 = human epithelial growth factor receptor 2 .

\begin{tabular}{|c|c|c|c|c|c|c|c|c|}
\hline \multirow{2}{*}{ Age at surgery, n (\%) } & \multicolumn{2}{|c|}{$1975-1982(n=575)$} & \multicolumn{2}{|c|}{$1983-1990(n=467)$} & \multicolumn{2}{|c|}{$1991-1998(\mathrm{n}=304)$} & \multicolumn{2}{|c|}{$1999-2006(n=118)$} \\
\hline & & & & & & & & \\
\hline$<40$ & 50 & $(8.7)$ & 57 & $(12.2)$ & 43 & $(14.1)$ & 15 & $(12.7)$ \\
\hline $40-49$ & 146 & $(25.4)$ & 90 & (19.3) & 76 & $(25.0)$ & 21 & $(17.8)$ \\
\hline $50-59$ & 196 & $(34.1)$ & 148 & (31.7) & 82 & $(27.0)$ & 28 & $(23.7)$ \\
\hline $60-69$ & 117 & $(20.3)$ & 109 & $(23.3)$ & 66 & $(21.7)$ & 30 & $(25.4)$ \\
\hline $70+$ & 66 & $(11.5)$ & 63 & $(13.5)$ & 37 & $(12.2)$ & 24 & $(20.3)$ \\
\hline \multicolumn{9}{|l|}{ Time to metastases, $\mathrm{n}(\%)$} \\
\hline $0-1$ years & 107 & $(18.6)$ & 77 & $(16.5)$ & 34 & $(11.2)$ & 25 & $(21.2)$ \\
\hline $1-2$ years & 128 & $(22.3)$ & 104 & $(22.3)$ & 69 & $(22.7)$ & 28 & $(23.7)$ \\
\hline $2-5$ years & 190 & $(33.0)$ & 155 & $(33.2)$ & 112 & $(36.8)$ & 45 & $(38.1)$ \\
\hline $5+$ years & 150 & $(26.1)$ & 131 & $(28.1)$ & 89 & $(29.3)$ & 20 & (16.9) \\
\hline \multicolumn{9}{|l|}{ Site of metastasis, n (\%) } \\
\hline Bone & 65 & $(11.3)$ & 71 & $(15.2)$ & 49 & $(16.1)$ & 14 & $(11.9)$ \\
\hline Visceral & 510 & $(88.7)$ & 396 & $(84.8)$ & 255 & $(83.9)$ & 104 & $(88.1)$ \\
\hline \multicolumn{9}{|l|}{ Local recurrence, $\mathbf{n}(\%)$} \\
\hline No Local Rec & 270 & $(47.0)$ & 210 & $(45.0)$ & 198 & $(65.1)$ & 88 & $(74.6)$ \\
\hline Local $\operatorname{Rec}<2$ & 154 & $(26.8)$ & 129 & $(27.6)$ & 37 & $(12.2)$ & 15 & $(12.7)$ \\
\hline Local $\operatorname{Rec} \geq 2$ & 151 & $(26.3)$ & 128 & $(27.4)$ & 69 & $(22.7)$ & 15 & $(12.7)$ \\
\hline \multicolumn{9}{|l|}{ Nodal status, n (\%) } \\
\hline Negative & 155 & $(27.0)$ & 126 & $(27.0)$ & 67 & $(22.0)$ & 18 & $(15.3)$ \\
\hline Positive & 352 & $(61.2)$ & 296 & $(63.4)$ & 210 & $(69.1)$ & 87 & (73.7) \\
\hline Missing & 68 & $(11.8)$ & 45 & $(9.6)$ & 27 & $(8.9)$ & 13 & $(11.0)$ \\
\hline \multicolumn{9}{|c|}{ No of lymph nodes involved, $n$ (\%) } \\
\hline 0 & 155 & $(27.0)$ & 126 & $(27.0)$ & 67 & $(22.0)$ & 18 & $(15.3)$ \\
\hline $1-3$ & 167 & $(29.0)$ & 148 & $(31.7)$ & 100 & $(32.9)$ & 40 & $(33.9)$ \\
\hline $4+$ & 185 & $(32.2)$ & 148 & $(31.7)$ & 110 & $(36.2)$ & 47 & (39.8) \\
\hline Missing & 68 & $(11.8)$ & 45 & $(9.6)$ & 27 & $(8.9)$ & 13 & $(11.0)$ \\
\hline Tumour size, n (\%) & & & & & & & & \\
\hline$<2 \mathrm{~cm}$ & 111 & $(19.3)$ & 109 & $(23.3)$ & 105 & $(34.5)$ & 29 & $(24.6)$ \\
\hline $2-5 \mathrm{~cm}$ & 419 & (72.9) & 323 & $(69.2)$ & 172 & $(56.6)$ & 73 & $(61.9)$ \\
\hline $5+\mathrm{cm}$ & 30 & $(5.2)$ & 29 & $(6.2)$ & 22 & $(7.2)$ & 13 & $(11.0)$ \\
\hline Missing & 15 & $(2.6)$ & 6 & $(1.3)$ & 5 & $(1.6)$ & 3 & $(2.5)$ \\
\hline Histological type, n (\%) & & & & & & & & \\
\hline Ductal & 469 & $(81.6)$ & 382 & $(81.8)$ & 243 & $(79.9)$ & 93 & $(78.8)$ \\
\hline Lobular & 52 & $(9.0)$ & 61 & (13.1) & 33 & $(10.9)$ & 11 & $(9.3)$ \\
\hline Other/missing & 54 & $(9.4)$ & 24 & $(5.1)$ & 28 & $(9.2)$ & 14 & (11.9) \\
\hline Grade, $\mathbf{n}(\%)$ & & & & & & & & \\
\hline Grade 1 & 25 & $(4.3)$ & 19 & $(4.1)$ & 12 & (3.9) & 6 & $(5.1)$ \\
\hline Grade 2 & 260 & $(45.2)$ & 203 & (43.5) & 84 & $(27.6)$ & 28 & $(23.7)$ \\
\hline Grade 3 & 195 & (33.9) & 181 & $(38.8)$ & 168 & $(55.3)$ & 69 & $(58.5)$ \\
\hline Unknown/missing & 95 & (16.5) & 64 & (13.7) & 40 & $(13.2)$ & 15 & (12.7) \\
\hline ER-status, n (\%) & & & & & & & & \\
\hline Negative & 188 & $(32.7)$ & 144 & $(30.8)$ & 92 & $(30.3)$ & 41 & $(34.7)$ \\
\hline Positive & 321 & $(55.8)$ & 302 & $(64.7)$ & 186 & $(61.2)$ & 71 & $(60.2)$ \\
\hline Missing data & 66 & (11.5) & 21 & $(4.5)$ & 26 & $(8.6)$ & 6 & $(5.1)$ \\
\hline PgR-status, n (\%) & & & & & & & & \\
\hline Negative & 266 & $(46.3)$ & 239 & $(51.2)$ & 140 & $(46.1)$ & 60 & $(50.8)$ \\
\hline Positive & 210 & (36.5) & 206 & $(44.1)$ & 138 & $(45.4)$ & 52 & $(44.1)$ \\
\hline Missing data & 99 & $(17.2)$ & 22 & $(4.7)$ & 26 & $(8.6)$ & 6 & $(5.1)$ \\
\hline HER2-status, n (\%) & & & & & & & & \\
\hline Negative & 191 & $(33.2)$ & 216 & $(46.3)$ & 154 & $(50.7)$ & 58 & $(49.2)$ \\
\hline Positive & 58 & $(10.1)$ & 79 & (16.9) & 65 & $(21.4)$ & 38 & $(32.2)$ \\
\hline Missing data & 326 & $(56.7)$ & 172 & $(36.8)$ & 85 & $(28.0)$ & 22 & $(18.6)$ \\
\hline High risk subpopulation ${ }^{a}$ & & & & & & & & \\
\hline St Gallen 'High Risk' + Grade 3 & 98 & $(17.0)$ & 101 & $(21.6)$ & 91 & $(29.9)$ & 52 & $(44.1)$ \\
\hline Other/missing & 477 & $(83.0)$ & 366 & $(78.4)$ & 213 & $(70.1)$ & 66 & $(55.9)$ \\
\hline Surgery, n (\%) & & & & & & & & \\
\hline Mastectomy & 485 & $(84.3)$ & 265 & $(56.7)$ & 159 & $(52.3)$ & 68 & $(57.6)$ \\
\hline Breast conservation & 90 & $(15.7)$ & 202 & $(43.3)$ & 145 & $(47.7)$ & 50 & $(42.4)$ \\
\hline Radiation therapy ${ }^{\mathrm{b}}, \mathrm{n}(\%)$ & & & & & & & & \\
\hline Yes & 286 & $(49.7)$ & 275 & $(58.9)$ & 205 & $(67.4)$ & 95 & $(80.5)$ \\
\hline No & 289 & $(50.3)$ & 192 & $(41.1)$ & 99 & $(32.6)$ & 23 & $(19.5)$ \\
\hline Endocrine therapy ${ }^{\mathrm{b}}, \mathrm{n}(\%)$ & & & & & & & & \\
\hline Yes & 255 & $(44.3)$ & 274 & $(58.7)$ & 258 & $(84.9)$ & 72 & $(61.0)$ \\
\hline No & 320 & $(55.7)$ & 193 & $(41.3)$ & 46 & $(15.1)$ & 46 & $(39.0)$ \\
\hline Chemotherapy $^{\mathrm{b}}, \mathbf{n}(\%)$ & & & & & & & & \\
\hline Yes & 136 & $(23.7)$ & 143 & $(30.6)$ & 183 & $(60.2)$ & 81 & $(68.6)$ \\
\hline No & 439 & (76.3) & 324 & $(69.4)$ & 121 & $(39.8)$ & 37 & $(31.4)$ \\
\hline
\end{tabular}

a Based on the mean of 5 imputation datasets.

b Including treatment to the primary tumour and treatment for local recurrence. 


\section{A. Whole patient cohort}

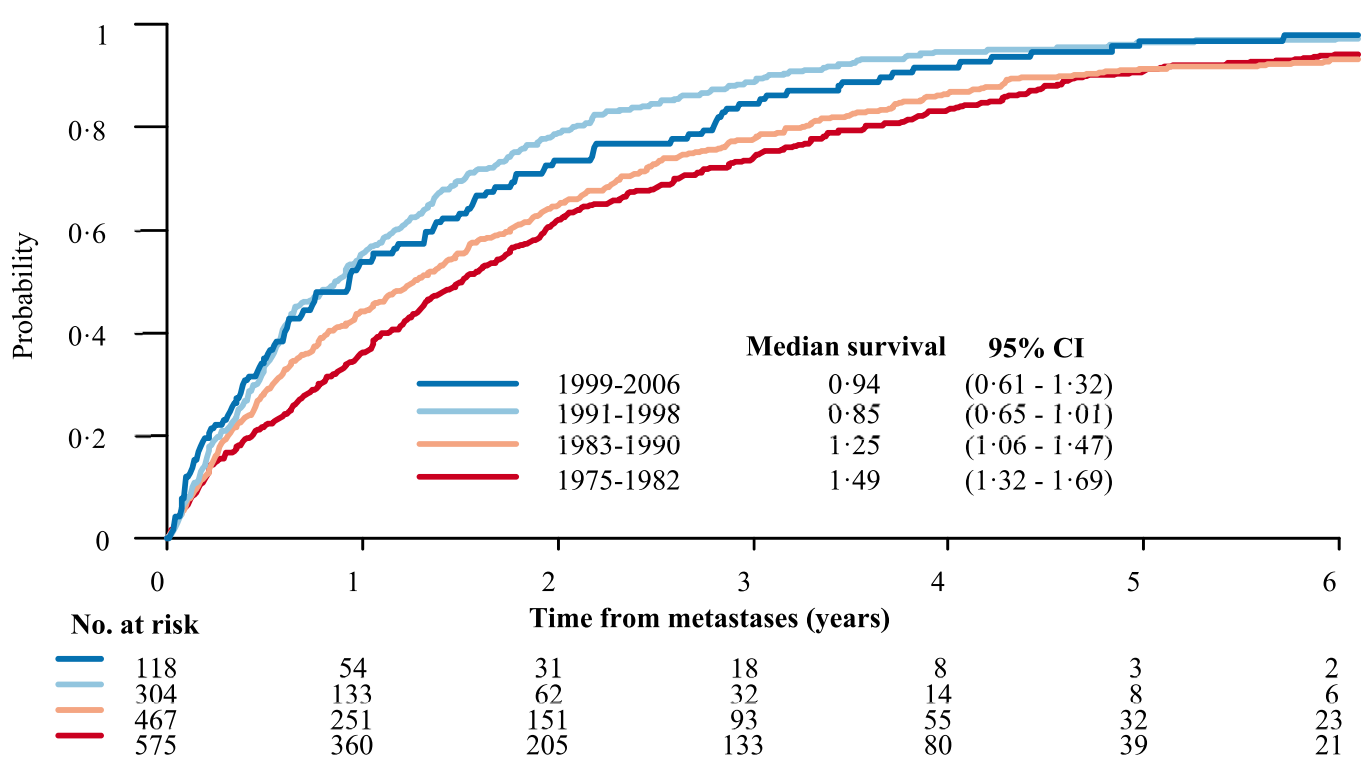

\section{B. High-risk subpopulation}

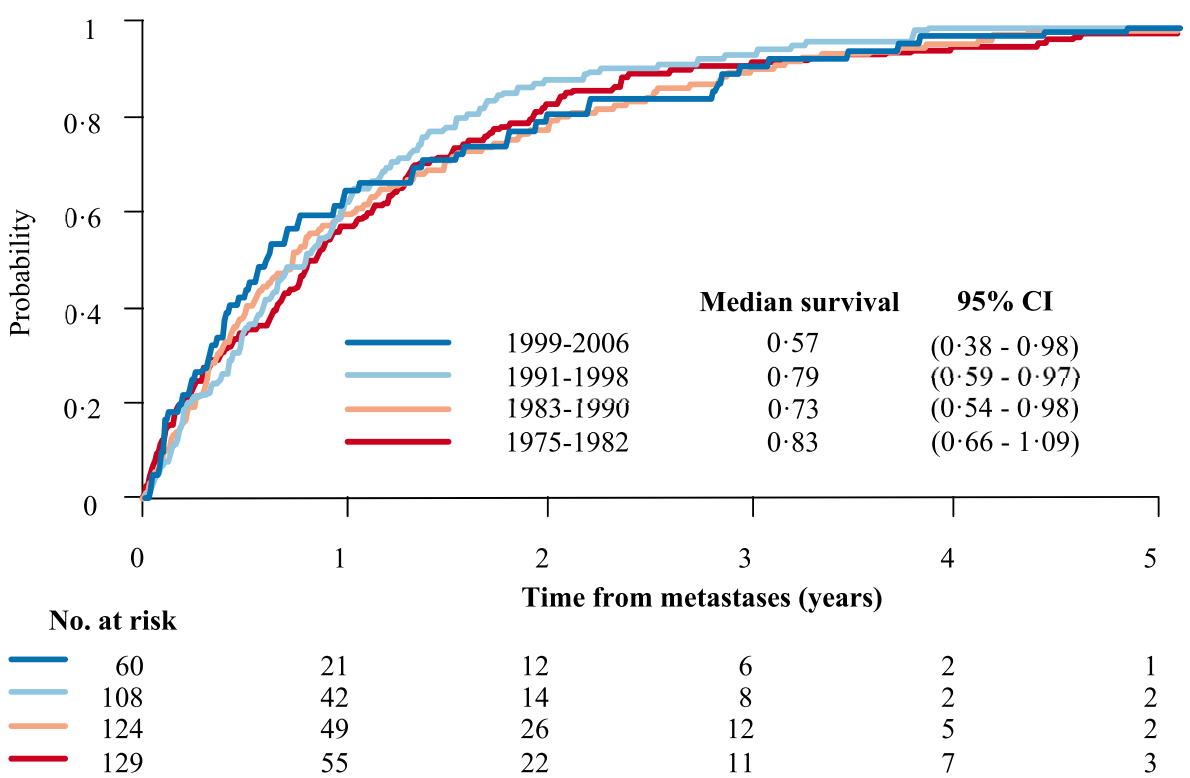

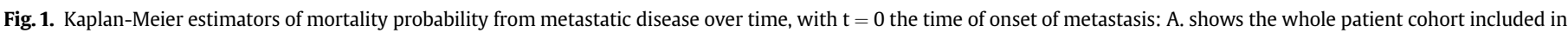

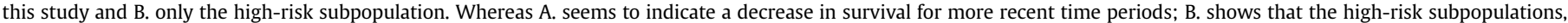

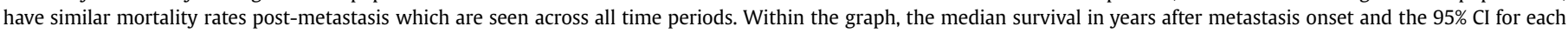
time period is presented. Below the graph are the figures for the absolute number of patients at risk.

role of adjuvant treatment was given by Fink [33].

This poorer post-metastatic overall could possibly be explained by adjuvant systemic treatment, as inherently adjuvant systemic treatment is given to higher risk tumours. Less malignant tumour cells are eliminated leaving only the most aggressive clones of tumour cells. Adjuvant systemic treatment-induced resistance may occur in those remaining clones of tumour cells, as they have had prior exposure to the adjuvant systemic treatment. Re-exposure to chemotherapy is less effective. This effect is seen in women treated with doxorubicin and taxanes or Cyclophosphamide Methotrexate Fluorouracil (CMF) - the so-called ATRESS phenomenon (adjuvant therapy-related shortening of survival). The administration of these drugs to treat primary breast cancer has been suggested to decrease overall survival from the time of diagnosis of metastatic disease by one-third [31-33,35-37,39]. We have found a similar one-third reduction in post-metastatic survival when comparing P1 to P4 $[35,37]$. Of note, in the first cohort, taxanes and anthracyclines were not clinically available for adjuvant treatment of primary breast 
Table 6

Hazard ratios of mortality after the onset of metastasis for each cohort, with a median follow-up of 1.2 years $(\mathrm{Q} 1=0.44$ years, Q3 $=2.4$ years).

\begin{tabular}{|c|c|c|c|c|c|c|c|c|}
\hline \multirow{2}{*}{$\begin{array}{l}\text { Model } \\
1\end{array}$} & \multicolumn{3}{|c|}{$\begin{array}{l}\text { 1975-1982 (number of } \\
\text { deaths: } 517 \text { ) }\end{array}$} & \multirow{2}{*}{$\begin{array}{l}\text { 1983-1990 (number of } \\
\text { deaths: } 428) \\
(0.98-1.26)\end{array}$} & \multicolumn{2}{|c|}{$\begin{array}{l}\text { 1991-1998 (number of } \\
\text { deaths: } 292 \text { ) }\end{array}$} & \multicolumn{2}{|c|}{ 1999-2006 (number of deaths: 113 ) } \\
\hline & 1.00 & Ref. & 1.11 & & 1.57 & $(1.36-1.82)$ & 1.43 & $(1.18-1.74)$ \\
\hline 2 & 1.00 & Ref. & 1.17 & $(1.03-1.34)$ & 1.78 & $(1.54-2.06)$ & 1.41 & $(1.15-1.71)$ \\
\hline 3 & 1.00 & Ref. & 1.15 & $(1.01-1.30)$ & 1.56 & $(1.34-1.82)$ & 1.27 & $(1.03-1.55)$ \\
\hline 4 & 1.00 & Ref. & 1.18 & $(1.03-1.34)$ & 1.63 & $(1.39-1.90)$ & 1.28 & $(1.05-1.58)$ \\
\hline 5 & 1.00 & Ref. & 1.10 & $(0.95-1.26)$ & 1.23 & $(1.00-1.51)$ & 1.02 & $(0.80-1.31)$ \\
\hline 6 & 1.00 & Ref. & 1.09 & $(0.95-1.25)$ & 1.23 & $(1.00-1.52)$ & 1.01 & $(0.79-1.29)$ \\
\hline 7 & 1.00 & Ref. & 1.06 & $(0.93-1.22)$ & 1.13 & $(0.92-1.40)$ & 0.94 & $(0.73-1.21)$ \\
\hline
\end{tabular}

Model 1: Crude analysis.

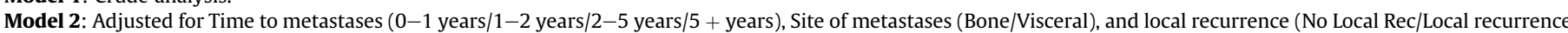
within 2 years/Local recurrence later than 2 years).

Model 3: As Model2 with further adjustment for Tumour size ( $<2 \mathrm{~cm} / 2-5 \mathrm{~cm} / 5+\mathrm{cm}$ ), Nodal status (Negative/Positive), and Tumour grade (Grade $1 /$ Grade $2 /$ Grade 3 ).

Model 4: As Model3 with further adjustment for Histological type (Ductal/Lobular/Other), ER-status (Negative/Positive), and PgR-status (Negative/Positive).

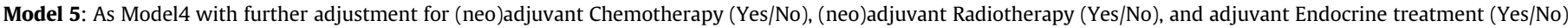
regarding primary tumour.

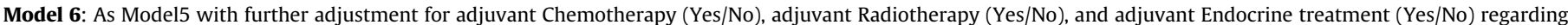
local recurrence.

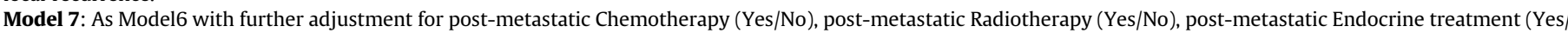
No), and anti-body treatment (Yes/No) regarding distant metastases.
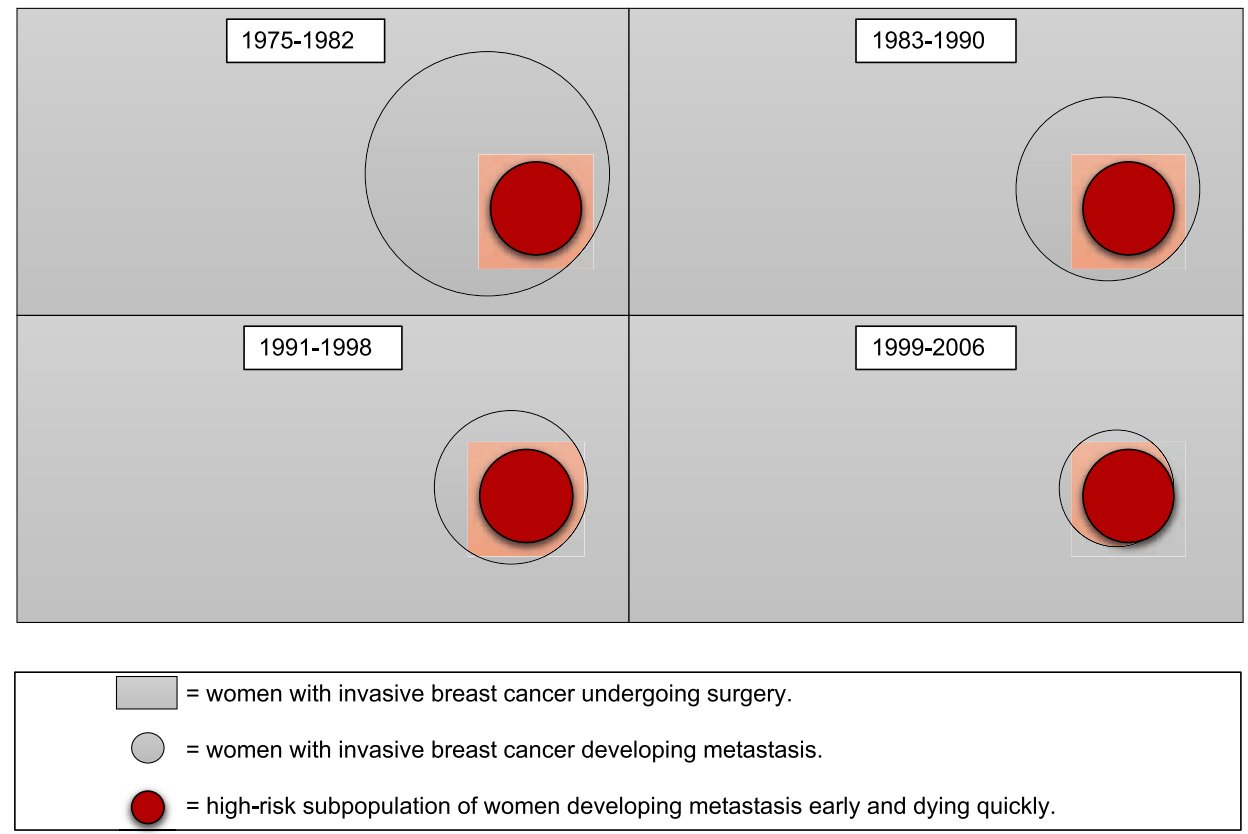

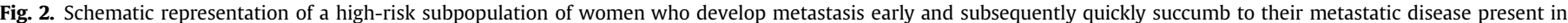
every cohort. The presence of these women with poor prognosis is obscured in earlier cohorts due to the number of women developing metastasis then.

cancer $[40,41]$. It is probable that the addition of adjuvant taxanes could further diminish post-metastatic survival [36]. Moreover, the HR for metastatic survival diminishing to approximately 1.00 in P4 when adjusted for treatment to the primary tumour makes it probable that effectively the difference in survival from time of metastasis between the women within the four different time periods is related to their response to differences in treatment regimens to the primary tumour (adjustment model 5 in Table 6). This phenomenon has also been demonstrated in other solid tumours, e.g. colorectal cancer [42]. It is probable that applying a selective pressure such as chemotherapy could cause the emergence of treatment-resistant clones [43]. As the use of chemotherapy is disputed for lobular breast cancer [44], sub-analyses of women with lobular breast cancer was performed. The data showed wide confidence intervals, indicating limit power and therefore no meaningful conclusions could be drawn.

\subsection{Strengths and weaknesses}

Other studies [17,20,34,37,45,46] have described changes in the clinical pattern of breast cancer and metastatic breast cancer over a short-to-medium term, though none have reported such a large cohort of breast cancer patients, including systemic treatment details, from a single centre over an extensive period of 40 years.

The data in this study has been prospectively recorded since the establishment of the breast cancer database at Guy's Hospital, providing complete and reliable clinical data. The data has been collected in one centre, which may limit the generalisability of the results but, conversely, ensures a relatively consistent patient population over time.

Significant changes have taken place in the past four decades in both diagnostic and treatment modalities and management protocols for breast cancer. By adjusting for predetermined 
confounding factors these variations in diagnosis and treatment have been partly mitigated.

\section{Conclusions}

Although the risk of developing metastasis has decreased and overall survival from breast cancer has improved over the last four decades, there remains a group of women who develop metastasis early and in whom prognosis remains poor. This could potentially be a result of adjuvant systemic treatment-induced resistance seen in those treated with doxorubicin, taxanes or Cyclophosphamide Methotrexate Fluorouracil - the so-called ATRESS phenomenon which merits further investigation. The next step will be to identify a molecular signature in treatment resistant women, intersecting with the high-risk subgroup of women, to define better targeted treatment options.

\section{Sources of support}

No support has been received to conduct this research.

\section{Declaration of competing interest}

The authors declare no conflict of interest.

\section{Appendix A. Supplementary data}

Supplementary data to this article can be found online at https://doi.org/10.1016/j.breast.2020.01.006.

\section{References}

[1] Cancer Research UK. Breast cancer survival statistics. 2018. http://www. cancerresearchuk.org/health-professional/cancer-statistics/statistics-bycancer-type/breast-cancer/incidence-invasive. [Accessed 1 January 2017].

[2] Verrill M. Chemotherapy for early-stage breast cancer: a brief history. Br J Canc 2009;101:S2-5. https://doi.org/10.1038/sj.bjc.6605268.

[3] Smith E. Cancer Research UK. Tamoxifen - the start of something big. http:// scienceblog.cancerresearchuk.org/2012/10/15/high-impact-sciencetamoxifen-the-start-of-something-big/; Oct 152012.

[4] Zurrida S, Veronesi U. Milestones in breast cancer treatment. Breast J 2015;21: 3-12. https://doi.org/10.1111/tbj.12361.

[5] Great britain. Department of Health and social security. Working group on breast cancer screening, forrest P. Breast cancer screening: report to the Health ministers of england, wales, scotland \& Northern Ireland/by a working group chaired by sir patrick forrest. 1986 .

[6] Verweij J, De Jonge MJA. Achievements and future of chemotherapy. Eur J Cancer 2000;36:1479-87. https://doi.org/10.1016/S0959-8049(00)00133-7.

[7] Harvey JM, Clark GM, Osborne CK, Allred DC. Estrogen receptor status by immunohistochemistry is superior to the ligand-binding assay for predicting response to adjuvant endocrine therapy in breast cancer. J Clin Oncol 1999;17. https://doi.org/10.1200/JCO.1999.17.5.1474. 1474-1474.

[8] Shousha S. Oestrogen receptor status of breast carcinoma: Allred/H score conversion table. Histopathology 2008;53:346-7. https://doi.org/10.1111/ j.1365-2559.2008.03075.x.

[9] Chen JQ, Litton J, Xiao L, Zhang HZ, Warneke CL, Wu Y, et al. Quantitative immunohistochemical analysis and prognostic significance of TRPS-1, a new GATA transcription factor family member, in breast cancer. Horm Cancer 2010;1:21-33. https://doi.org/10.1007/s12672-010-0008-8.

[10] Purushotham A, Shamil E, Cariati M, Agbaje O, Muhidin A, Gillett C, et al. Age at diagnosis and distant metastasis in breast cancer-a surprising inverse relationship. Eur J Cancer 2014;50:1697-705. https://doi.org/10.1016 j.ejca.2014.04.002

[11] Rakha EA, Pinder SE, Bartlett JMS, Ibrahim M, Starczynski J, Carder PJ, et al. Updated UK Recommendations for HER2 assessment in breast cancer. J Clin Pathol 2015;68:93-9. https://doi.org/10.1136/jclinpath-2014-202571.

[12] Nitta H, Kelly BD, Allred C, Jewell S, Banks P, Dennis E, et al. The assessment of HER2 status in breast cancer: the past, the present, and the future. Pathol Int 2016;66:313-24. https://doi.org/10.1111/pin.12407.

[13] Goldhirsch A, Wood WC, Gelber RD, Coates AS, Thu B, Senn H-J, et al. Progress and promise: highlights of the international expert consensus on the primary therapy of early breast cancer 2007. Ann Oncol 2007;18:1133-44. https:/ doi.org/10.1093/annonc/mdm271.

[14] Jemal A, Ward EM, Johnson CJ, Cronin KA, Ma J, Ryerson AB, et al. Annual report to the nation on the status of cancer, 1975-2014, featuring survival.
J Natl Cancer Inst 2017;109. https://doi.org/10.1093/jnci/djx030.

[15] Autier Research Director P, Boniol Senior Statistician M, Gavin Director A Vatten Professor LJ. Breast cancer mortality in neighbouring European countries with different levels of screening but similar access to treatment: trend analysis of WHO mortality database n.d. doi:10.1136/bmj.d4411.

[16] Bennett RL, Blanks RG, Patnick J, Moss SM. Results from the UK NHS breast screening Programme 2000-05. J Med Screen 2007;14:200-4. https://doi.org/ 10.1258/096914107782912068.

[17] Early Breast Cancer Trialists' Collaborative Group (EBCTCG). Effects of chemotherapy and hormonal therapy for early breast cancer on recurrence and 15-year survival: an overview of the randomised trials. Lancet 2005;365: 1687-717. https://doi.org/10.1016/S0140-6736(05)66544-0.

[18] Balduzzi S, Mantarro S, Guarneri V, Tagliabue L, Pistotti V, Moja L, et al. Trastuzumab-containing regimens for metastatic breast cancer. In: Moja L, editor. Cochrane database syst. Rev. Chichester, UK: John Wiley \& Sons, Ltd; 2014. CD006242. https://doi.org/10.1002/14651858.CD006242.pub2.

[19] Moja L, Tagliabue L, Balduzzi S, Parmelli E, Pistotti V, Guarneri V, et al. Trastuzumab containing regimens for early breast cancer. In: Moja L, editor. Cochrane database syst. Rev. Chichester, UK: John Wiley \& Sons, Ltd; 2012. CD006243. https://doi.org/10.1002/14651858.CD006243.pub2.

[20] Early Breast Cancer Trialists' Collaborative Group (EBCTCG), Darby S, McGale P, Correa C, Taylor C, Arriagada R, et al. Effect of radiotherapy after breast-conserving surgery on 10-year recurrence and 15-year breast cancer death: meta-analysis of individual patient data for 10801 women in 17 randomised trials. Lancet 2011;378:1707-16. https://doi.org/10.1016/S01406736(11)61629-2.

[21] Veronesi U, Cascinelli N, Mariani L, Greco M, Saccozzi R, Luini A, et al. Twentyyear follow-up of a randomized study comparing breast-conserving surgery with radical mastectomy for early breast cancer. N Engl J Med 2002;347: 1227-32. https://doi.org/10.1056/NEJMoa020989.

[22] Fisher B, Anderson S. Twenty-year follow-up of a randomized trial comparing total mastectomy, lumpectomy, and lumpectomy plus irradiation for the treatment of invasive breast cancer. N Engl J Med 2002;347:1233-41.

[23] Cetin K, Christiansen CF, Svaerke C, Jacobsen JB, Sorensen HT. Survival in patients with breast cancer with bone metastasis: a Danish population-based cohort study on the prognostic impact of initial stage of disease at breast cancer diagnosis and length of the bone metastasis-free interval. BMJ Open 2015;5. https://doi.org/10.1136/bmjopen-2015-007702. e007702-e007702.

[24] Solomayer EF, Diel IJ, Meyberg GC, Gollan C, Bastert G. Metastatic breast cancer: clinical course, prognosis and therapy related to the first site of metastasis. Breast Canc Res Treat 2000;59:271-8.

[25] Ren Z, Li Y, Hameed O, Siegal GP, Wei S. Prognostic factors in patients with metastatic breast cancer at the time of diagnosis. Pathol Res Pract 2014;210: 301-6. https://doi.org/10.1016/j.prp.2014.01.008.

[26] Ahmed ARH. HER2 expression is a strong independent predictor of nodal metastasis in breast cancer. J Egypt Natl Cancer Inst 2016;28:219-27. https:// doi.org/10.1016/j.jnci.2016.09.002.

[27] Andre F, Slimane K, Bachelot T, Dunant A, Namer M, Barrelier A, et al. Breast cancer with synchronous metastases: trends in survival during a 14-year period. J Clin Oncol 2004;22:3302-8. https://doi.org/10.1200/ CO.2004.08.095.

[28] Giordano SH, Buzdar AU, Smith TL, Kau S-W, Yang Y, Hortobagyi GN. Is breast cancer survival improving? Cancer 2004;100:44-52. https://doi.org/10.1002/ cncr.11859.

[29] Ernst MF, van de Poll-Franse LV, Roukema JA, Coebergh JWW, van Gestel CMJ, Vreugdenhil G, et al. Trends in the prognosis of patients with primary metastatic breast cancer diagnosed between 1975 and 2002. Breast 2007;16: 344-51. https://doi.org/10.1016/j.breast.2007.01.001.

[30] Chia SK, Speers CH, D'Yachkova Y, Kang A, Malfair-Taylor S, Barnett J, et al. The impact of new chemotherapeutic and hormone agents on survival in a population-based cohort of women with metastatic breast cancer. Cancer 2007;110:973-9. https://doi.org/10.1002/cncr.22867.

[31] Fink MK, Kleeberg UR, Bartels S. Adjuvant therapy-related shortening of survival (ATRESS): an underrated phenomenon. The Oncologist 2015;20:88. https://doi.org/10.1634/theoncologist.2014-0273.

[32] Fink MK, Kleeberg UR, Bartels S. Adjuvant therapy reduces rate of dissemination but shortens survival thereafter. The Oncologist 2015;20. https:// doi.org/10.1634/theoncologist.2015-0116. e23-e23.

[33] Fink MK. Does adjuvant therapy reduce postmetastatic survival? Ann Oncol 2019;30:1184-8. https://doi.org/10.1093/annonc/mdz201.

[34] Hölzel D, Eckel R, Bauerfeind I, Baier B, Beck T, Braun M, et al. Improved systemic treatment for early breast cancer improves cure rates, modifies metastatic pattern and shortens post-metastatic survival: 35-year results from the Munich Cancer Registry. J Cancer Res Clin Oncol 2017;143:1701-12. https://doi.org/10.1007/s00432-017-2428-0.

[35] Seidman AD, Chan S, Wang J, Zhu C, Xu C, Xu B. A pooled analysis of gemcitabine plus docetaxel versus capecitabine plus docetaxel in metastatic breast cancer. The Oncologist 2014;19:443-52. https://doi.org/10.1634/theoncologist.2013-0428.

[36] Pierga J-Y, Asselain B, Jouve M, Diéras V, Carton M, Laurence V, et al. Effect of adjuvant chemotherapy on outcome in patients with metastatic breast carcinoma treated with first-line doxorubicin-containing chemotherapy. Cancer 2001:91:1079-89. https://doi.org/10.1002/1097-0142(20010315)91:6<1079. AID-CNCR1103>3.0.CO;2-S

[37] Kleeberg UR, Fink M, Tessen H-W, Nennecke A, Hentschel S, Bartels S. 
Adjuvant therapy reduces the benefit of palliative treatment in disseminated breast cancer - own findings and review of the literature. Onkologie 2013;36: 348-56. https://doi.org/10.1159/000351253.

[38] Miller K, Wang M, Gralow J, Dickler M, Cobleigh M, Perez EA, et al. Paclitaxel plus bevacizumab versus paclitaxel alone for metastatic breast cancer. N Engl ] Med 2007;357:2666-76. https://doi.org/10.1056/NEJMoa072113.

[39] Bonneterre J, Mercier M. Response to chemotherapy after relapse in patients with or without previous adjuvant chemotherapy for breast cancer. Cancer Treat Rev 1993;19:21-30. https://doi.org/10.1016/0305-7372(93)90004-B.

[40] Fisher B. Two months of doxorubicin-cyclophosphamide with and without interval reinduction therapy compared with 6 months of cyclophosphamide, methotrexate, and fluorouracil in positive-node breast cancer patients with tamoxifen-nonresponsive tumors: results from t. J Clin Oncol 1990;8: 1483-96. https://doi.org/10.1200/JCO.1990.8.9.1483.

[41] Elzaafarany OH, Abusanad A. The magnitude of benefit from adding taxanes to anthracyclines in the adjuvant settings of breast cancer: discussion of large trials and meta-analyses. J Cancer Metastasis Treat 2018;4:14. https://doi.org/ 10.20517/2394-4722.2017.55.

[42] Andreou A, Kopetz S, Maru DM, Chen SS, Zimmitti G, Brouquet A, et al.
Adjuvant chemotherapy with FOLFOX for primary colorectal cancer is associated with increased somatic gene mutations and inferior survival in patients undergoing hepatectomy for metachronous liver metastases. Ann Surg 2012;256:642-50. https://doi.org/10.1097/SLA.0b013e31826b4dcc.

[43] Yates LR, Gerstung M, Knappskog S, Desmedt C, Gundem G, Van Loo P, et al. Subclonal diversification of primary breast cancer revealed by multiregion sequencing. Nat Med 2015;21:751-9. https://doi.org/10.1038/nm.3886.

[44] Kizy S, Huang JL, Marmor S, Tuttle TM, Hui JYC. Impact of the 21-gene recurrence score on outcome in patients with invasive lobular carcinoma of the breast. Breast Canc Res Treat 2017;165:757-63. https://doi.org/10.1007/ s10549-017-4355-9.

[45] Cortesi L, Toss A, Cirilli C, Marcheselli L, Braghiroli B, Sebastiani F, et al. Twenty-years experience with de novo metastatic breast cancer. Int J Cancer 2015;137:1417-26. https://doi.org/10.1002/ijc.29503.

[46] Vaz-Luis I, Lin NU, Keating NL, Barry WT, Winer EP, Freedman RA. Factors associated with early mortality among patients with de novo metastatic breast cancer: a population-based study. The Oncologist 2017;22:386-93. https:// doi.org/10.1634/theoncologist.2016-0369. 